ello, nos recuerda la presencia de narcóticos en la literatura a partir del siglo XVIII, ligada al comercio mundial y a la dominación geopolítica de Europa imperial (241).

Jorge Chen Sham

Universidad de Costa Rica

Miembro correspondiente Academia Nicaragüense de la Lengua

Miembro correspondiente Academia Norteamericana de la Lengua Española

\title{
Lope de Vega. Las bodas entre el Alma y el Amor Divino. El hijo pródigo. Edición de J. Enrique Duarte. Kassel: Reichenberger, 2017, 282 páginas
}

La edición de los "Autos sacramentales" de Lope de Vega tiene en este primer volumen un loable e ingente esfuerzo que termina por justificar la necesidad de publicar este corpus de piezas menores dramáticas con "suficiente anotación que proporcione al lector moderno los instrumentos textuales para entender su riqueza" (13). Se trata del primer volumen que firma y edita J. Enrique Duarte y que contempla, para este caso, la edición crítica de los siguientes autos sacramentales, Las bodas entre el Alma y el Amor Divino y El hijo pródigo, los cuales aparecen insertados en El peregrino en su patria (1604) de Lope de Vega.

La edición ofrecida por Duarte es impecable, profusa en notas y en detalles explicativos para comprender la red de alusiones históricas, idiomáticas y culturales sobre las que se sostiene el entramado bíblico y teológico de estos autos, aunque a veces se apegue tanto a ese guion filológico en el que las sendas introducciones a las piezas desemboca para presentar un cierto mecanicismo (esquema métrico, síntesis argumental, crítica, variantes, ediciones modernas) del que es difícil, hay que confesarlo, sustraerse también. El apartado 7, "Estudio textual conjunto: Las bodas y El hijo pródigo" (27-40), permite comparar el texto base que ofrece Duarte para explicar las erratas y variaciones en relación con la príncipe; pero echo de menos un elemento de peso en la historia literaria y la recepción textual de estos autos sacramentales y que hubiera podido Duarte, al menos, dedicarle unos párrafos.

Como él indica son dos autos sacramentales que aparecen insertados en un texto mayor, El peregrino en su patria, respectivamente, al final del "Libro segundo", acota para Las bodas (17), mientras que para el segundo, El hijo pródigo, extrañamente no lo indica. Entonces, son piezas que, si bien es cierto pueden leerse e interpretarse independientemente y pueden por lo consiguiente adquirir una autonomía textual, deberían ubicarse primeramente en esa novela de tipo bizantino que las cobija y les da su coherencia argumentativa y estilística. Porque sendos autos tienen una función en el clímax y acentuación no solo de las emociones/ pasiones del conflicto psicológico de los personajes en la novela de Lope de Vega, sino también de la experiencia propiamente religiosa, que ambas piezas resaltan y subrayan para que vengan a ser un soporte y un intensificador de lo que se juega en el plano narrativo.

En cuanto a los textos, en Las bodas entre el Alma y el Amor Divino el ambiente de epitalamio y de ambiente pastoril dominan para que se introduzca como tal la representación teatral, que el trono y la maquinaria refuerzan: la propaganda fidei y los personajes alegóricos se instauran en ese mundo de oposiciones morales que hace de la salvación divina el centro de ese camino para que el Alma inicie su periplo hacia la divinidad, el Amor Divino, crucificado y centro de la redención posible. Se trata de una pieza catequística, en donde todo está 
subordinado a lo doctrinario. Más interesante es El hijo pródigo, cuya dependencia intertextual con la parábola neotestamentaria nos hace descubrir una pieza de más intensidad humana, aunque el hipotexto encauza narrativamente la variante de Lope de Vega para que sea también la expresión del perdón y el arrepentimiento cristianos. Aquí hubiera sido importante explicar en qué momento y en qué situación de la novela bizantina aparece esta pieza, cuyo carácter doctrinario, fuerte y redundante, está asegurado en esa introducción de músicos y del personaje del "Prólogo"; su peso ideológico dentro del tópico del desengaño barroco es innegable. Al fin y al cabo esa carga moral y catequística es lo que más llama la atención al lector moderno para el cual estas piezas son de difícil recepción frente a la desacralización galopante de la vida contemporánea. Esperamos los siguientes volúmenes de la colección.

Jorge Chen Sham

Universidad de Costa Rica

Miembro correspondiente Academia Nicaragüense de la Lengua Miembro correspondiente Academia Norteamericana de la Lengua Española 